\title{
What has the Bologna Declaration Brought us?
}

Dear readers,

it has been 13 years since the signature of the Bologna Declaration. When we consider main goals, which stand behind this declaration and other documents that followed, the effort to develop higher education in the EU cannot be denied. Yet even after 13 years the question still remains, if the ways this process is based on, are right for reaching these achievements.

In this short text it is impossible to analyze all areas that were affected by the Bologna Declaration, so let us try to focus rather on the main philosophy of this process and review the most apparent achievements.

Despite partial problems, the official documents mostly highlight the significant progress, which was accomplished. "From almost exclusively national systems of higher education, which had differed in structure of the studies and whose study programs were hard to compare ... a system of national systems with a relatively harmonized structure arranged into three levels - bachelor, master and doctorate - was established."1. This evaluation relatively clearly shows the way the Bologna process has mainly taken - unification of structure of higher education and principles, on which the higher education is built. It might have made the life of statisticians easier in monitoring of the results, but an unanswered question remains whether this process has contributed to the development and higher quality of higher education in Europe. We do not want at all to question the development of international cooperation of universities and a significant growth in students' exchanges that has taken place in the past period. Nevertheless, in this field the importance of formal unification of higher education is being overestimated. Also, as last discussions about the EU budget shows that e.g. for the development of students exchanges, financial support is the crucial and "unified" credit system is left behind on the second place.

1 Viz MŠMT ČR: Bologna Process. [on-line], Praha, Ministry of Education, Youth and Sports of the Czech Republic, c2012, [cit. 10. 6. 2012], 〈http://bologna.msmt.cz〉. 
It is necessary to realize that this unification of the national systems has taken place on formal level but not on material level. Although we have three unified levels of higher education, European credit system, we come up with the same qualification frameworks etc., the result is not and also cannot be the same level of schools, of difficulty of studies, of the subject of studies etc.. In this context sometimes the overemphasized effort of formal unification is not only unnecessary, it also can mislead the attention from substantial content matters. The formal unification will never have the same meaning as the real unification. It is not a problem e.g. to formally unite the content of subjects. Still it will never mean, that whoever and wherever absolves the subject, will have the same knowledge. It always depends on the school tradition, teacher's personality, self-motivation and competition among students etc. Despite formally the same, the real result will be different.

Instead of trying to create a formal unification, we should focus on gaining more pieces of information about the content and quality of certain school, comparing their real level and interfacing different systems. The unification must take place where the competition among schools is present and represents the incentive. If some models show more viability, others will follow them. It is not our target to have unified schools, but to push the development through the competition. Its specialization and originality of a certain school is that which could lead the quality and development of higher education.

In our country the most apparent result of the Bologna process was the division of studies into three-levels with a pyramid structure of the number of students in each level. What has it brought us? It has brought us an amount of bachelors, who leave schools, although they know, they will not get another part of their studies and the praxis is still not willing to accept them in full extent. The idea of students' migration among bachelor and following master studies and among schools is fulfilled very, very little. The system of quotas for numbers of bachelor and master students does not allow schools to specialize noticeably in master studies and therefore the incentives and options for changing school for master studies are not sufficient. As well the idea of starting master studies after a few years of professional experience was dubious at the beginning (the longer the pause after completing a bachelor degree, the harder it is to manage more demanding subjects of master studies, starting in older age is hardly acceptable also because of financial reasons, leaving job and returning to studies is a change of lifestyle, which, after few years in 
business, hardly a few desire...). The separation of bachelor and master studies has brought more administrative burden for schools, but the real benefits for the development of quality of higher education remain somewhat hidden.

For European future, the education including higher education will be very important, if students, teachers and scientists have the opportunities to meet, it can among other things have a significant impact on the strengthening the perception of the sense of belonging in Europe, which deteriorates nowadays. The path does not run through expensive formal unification, which often discourages through its bureaucracy, but through strengthening of the autonomy and originality of schools, which will certainly find their own most effective forms and ways in cooperation under the growing competition on the field of education.

doc. Ing. Petr DVOř́́K, Ph.D.

Dean

Faculty of Finance and Accounting, University of Economics, Prague 